\title{
Commentary: Identifying patients who do not improve following surgical ventricular reduction: Is diastolic dysfunction the culprit?
}

\author{
Richard J. Moro, MBA, ACS, RDCS, RVT, ${ }^{\mathrm{a}}$ and Kevin D. Accola, MD, FACC ${ }^{\mathrm{b}}$
}

From the Departments of ${ }^{\mathrm{a}}$ Cardiovascular Ultrasound and ${ }^{\mathrm{b}}$ Thoracic/Cardiovascular Surgery, AdventHealth Orlando, Orlando, Fla.

Disclosures: Mr Moro is a consultant for Edwards Lifesciences, and Dr Accola is a consultant/speaker for Edwards LifeSciences.

Received for publication Oct 1, 2019; revisions received Oct 1, 2019; accepted for publication Oct 1, 2019; available ahead of print Oct 15, 2019.

Address for reprints: Kevin D. Accola, MD, FACC, AdventHealth Orlando, 217 Hillcrest St, Orlando, FL 32801 (E-mail: kaccola@cvsorlando.com).

J Thorac Cardiovasc Surg 2021;161:664-5

$0022-5223 / \$ 36.00$

Copyright (c) 2020 Published by Elsevier Inc. on behalf of The American Association for Thoracic Surgery https://doi.org/10.1016/j.jtcvs.2019.10.003

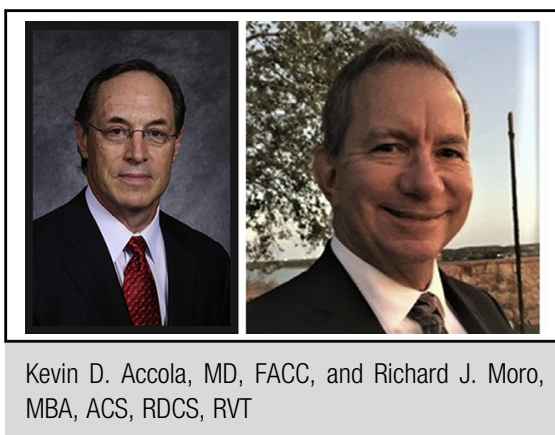

Central Message

Systolic function is life. Diastolic function is quality of life. Identifying positive cardiac function responders before SVR can predict improvements in NYHA class.

See Article page 651
In this issue of the Journal, an excellent retrospective observational study by Fantini and colleagues ${ }^{1}$ provides insight into a promising measurement identifying patients most likely to benefit from surgical ventricular reduction (SVR) for the treatment of ischemic cardiomyopathy presenting with severe diastolic dysfunction. Severe diastolic dysfunction is typically persistent and nonreversible even with optimal medical therapy or implantable devices. Each study patients' baseline presurgical echocardiogram demonstrated a restrictive filling pattern with an E/A ratio $\geq 2$ by pulse-wave Doppler, grade 3 diastolic dysfunction (the most severe by American Society of Echocardiography 2016 Guidance). ${ }^{2}$ Using the relative wall thickness (RWT) calculation $([2 *$ left ventricular $\{\mathrm{LV}\}$ posterior wall thickness]/LV diastolic diameter), the authors could differentiate with reasonable certainty diastolic performance responders and nonresponders. An RWT $\geq 0.32$ was indicative of postsurgical improvement in several diastolic markers and a change to grade 2 diastolic dysfunction.

When evaluating cardiac function, it is the ventricular contraction, the systolic event, that is most often referenced. It is easily observed and frequently visually estimated. Post SVR, both groups produced improvement in the ejection fraction but as Fantini and colleagues illustrate, only those with an RWT $\geq 0.32$ showed a sustained improvement in $\mathrm{E} / \mathrm{e}^{\prime}$ and $\mathrm{E} / \mathrm{A}$, suggesting LV reduced early diastolic filling pressures, compliance improvement, and normalization between passive and active filling phases of the LV. Both necessary components to diastolic health are best illustrated in the improvement in New York Heart Association functional class pre- and post-SVR comparisons between the 2 groups (Figure 3).

The importance of diastolic performance in patient surgical outcomes is not frequently taken into consideration.
Assessment is complicated and requires a multitude of different measurements and calculations to describe the pressure and compliance relationships between communicating structures, beginning with assessment of the inferior vena cava for estimation of the right atrial pressure and not complete until after systemic vascular resistance has been considered. ${ }^{3}$ Fantini and colleagues describe a simple, single calculation easily applied using standard echocardiogram imaging techniques and measurements.

Systolic function is life. Diastolic function is quality of life.

Future studies should focus on several topics. As noted by the authors, their patient population was primarily male; can the same parameter be used to identify female responders? What is the status of left atrial (LA) contractile function pre- and post-SVR? LA ejection fraction and Doppler calculations describing the pulmonary venous and LA relationship may be helpful, in addition to New York Heart Association classification including 6-minute walk test evaluation. What does this mean for other ventricular remodeling surgeries, and can this information be used with other myocardial pathologies such as hypertrophic obstructive cardiomyopathies?

We believe this important contribution of Fantini and colleagues may assist in the evaluation and expectations of 
treatment strategies associated with these complex patients experiencing ventricular dysfunction.

\section{References}

1. Fantini F, Toso A, Menicanti L, Moroni F, Castevecchio S. Restrictive filling pattern in ischemic cardiomyopathy: insights after surgical ventricular restoration. J Thorac Cardiovasc Surg. 2021;161:651-60.
2. Nagueh SF, Smiseth OA, Appleton CP, Byrd BF III, Dokainish H, Edvardsen T, et al. Recommendations for the evaluation of left ventricular diastolic function by echocardiography: an update from the American Society of Echocardiography and the European Association of Cardiovascular Imaging. J Am Soc Echocardiogr. 2016;29:277-314.

3. Khouri SJ, Maly GT, Suh DD, Walsh TE. A practical approach to the echocardiographic evaluation of diastolic function. J Am Soc Echocardiogr. 2004; 17:290-7. 